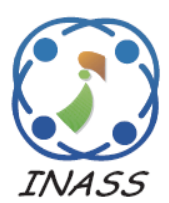

\title{
Comparative Study of Active Disturbance Rejection Control with RST Control for Variable Wind Speed Turbine Based on Doubly Fed Induction Generator Connected to the Grid
}

\author{
Mohssine Chakib $^{1 *} \quad$ Tamou Nasser $^{2} \quad$ Ahmed Essadki $^{1}$ \\ ${ }^{1}$ Laboratory of Research in Electrical Engineering, \\ High School of Technical Education, Mohammed V University, Rabat, Morocco \\ ${ }^{2}$ Laboratory of Research in Electrical Engineering, \\ Higher National School of Computer Science and Systems Analysis, Mohammed V University, Rabat, Morocco \\ * Corresponding author's Email: chakib1mohssine@gmail.com
}

\begin{abstract}
In this paper, we propose a new control strategy called linear active disturbance rejection control (ADRC) used to control the wind energy conversion system (WECS) based on doubly-fed induction generator (DFIG). This recent control strategy is compared with the conventional RST polynomial control method considered better and more efficient than the classical PI method according to different works. By the extended state observer ESO of the ADRC controller, the internal and the external disturbances on the system are estimated and compensated as a total disturbance in real time. Moreover, the proposed ADRC method is easy to tune and more practical which has only one tuning parameter. The RST controller has three polynomials chosen in order to reduce the effect of disturbance. These controllers have been used to control the stator powers of DFIG in order to extracting the maximum energy produced by the wind by using a maximum power point tracking (MPPT), to regulate the dc-link voltage in order to maintain DC bus voltage at constant value and to regulate the reactive power to ensure a unitary power factor. Then, these both control strategies are designed and their performances are compared in order to deduce the most efficient in terms of reference tracking and robustness. The simulation results prove that the proposed ADRC control technique is more robust and have better performance than the RST control.
\end{abstract}

Keywords: Wind energy conversion system (WECS), Active disturbance rejection control (ADRC), RST controller, DFIG, Extended state observer (ESO), Maximum power point tracking (MPPT).

\section{Introduction}

Today, the global wind power generation capacity has increased enormously and has developed rapidly compared to other renewable energy sources [1].

The doubly fed induction generator (DFIG) is the most widely used in larges wind turbines systems because this generator can operate at variable speed in order to extract maximum power from wind energy [2]; the rotor of the DFIG is connected to the grid by a back-to-back converter with a power about $30 \%$ of the DFIG capacity which ensures a compensation of the reactive power $[2,3]$.

However, the DFIG is subject to the effects of parametric uncertainties (due to saturation, overheating ...) and the effect of disturbance due to the speed variation, which could deflect the system from its optimal operate. This is why the control should be concerned with robustness and performance [4]. To do this, we referred to the use of the robust control.

Owing to the limitations posed by the conventional PI regulator and in order to have a more efficient and robust control of the wind chain; a new control strategy has been adopted. In order to 
prove its efficiency, the performances of the proposed controller (ADRC) have been compared to those of the robust polynomial RST controller. The RST controller is based on three polynomials R, S and $T$ chosen in order to reduce the effect of disturbance in reference signal tracking $[5,6]$.

The recent robust approach called ADRC control, proposed by Han in 1998 and evolved from PID, consists of the extended state observer (ESO). This observer can get the system status information in real time and it can obtain the real time actuating quantity of the internal and external disturbance which exists in object model [7]. Therefore, the ADRC achieves the functions of estimating and compensating the internal and external disturbances of systems [8]. This controller has many advantages such as good performance in case of dynamic system control, the high accuracy, good dynamic response, the system stability is guaranteed and the simplicity of the linear active disturbance reject controller implementation, whose the tuning parameters are reduced [7].

In this paper, These both ADRC and RST controllers are applied to control the rotor side converter in order to regulate the active and reactive powers exchanged between the stator of DFIG and the grid through controlling the rotor currents, and to control the grid-side converter in order to maintain DC bus voltage at constant value and ensure zero reactive power thus unitary power factor. Then the performances of these controllers are compared in term of reference tracking and in term of robustness against parameters variations of the system.

The rest of this paper is organized as follows. In Section 2, we begin with modeling of the different components of the wind energy conversion system as the turbine, the DFIG, back to back converter, grid filter and a DC link voltage. In Section 3, the Maximum Power Point Tracking (MPPT) technique is presented and applied to the turbine in order to extract the maximum power from the wind. Then the structure of both the RST and ADRC controllers are described. In Section 4 to 6 , these both controllers are applied to the wind energy conversion system in order to control of the DFIG, DC link voltage and grid filter. In the latest section, we present the results of simulation by MATLAB/Simulink environment using a $1.5 \mathrm{MW}$ DFIG wind turbine; these results are compared and discussed.

\section{Modeling of the wind energy conversion system}

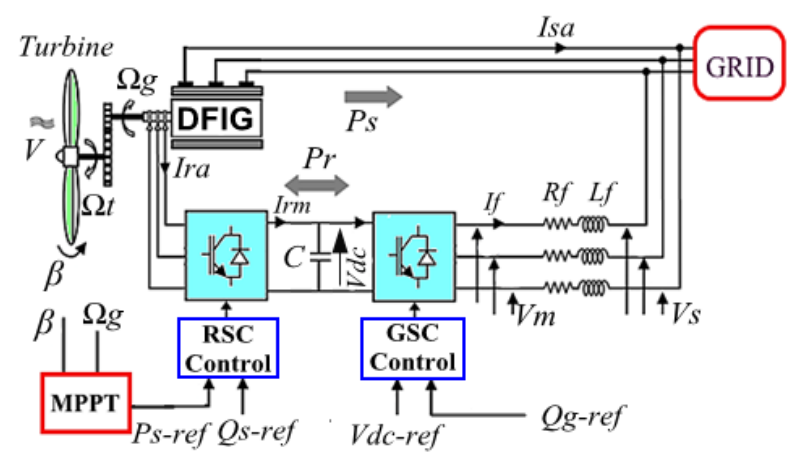

Figure.1 Model of the variable speed wind turbine conversion system based on DFIG

The Fig. 1 depicts the wind energy conversion system, which consists of a wind turbine coupled to the DFIG by gearbox, back-to-back converter and a grid filter $[1,9,13]$.

\subsection{Wind turbine modeling}

The following equation Eq. (1) represents the mechanical power captured by the wind turbine [9].

$$
P_{t}=\frac{1}{2} C_{p}(\lambda, \beta) \rho \pi R^{2} V^{3}
$$

Where:

$R$ : The turbine blade radius (m)

$\rho$ : The air density $(\mathrm{kg} / \mathrm{m} 3)$

$V$ : The wind speed $(\mathrm{m} / \mathrm{s})$

$\beta$ : the blade pitch angle (degree)

$C_{p}$ : The power coefficient, it is given by the following equation $[3,4,10]$ :

$$
C_{p}=0.5176\left(\frac{116}{\lambda_{i}}-0.4 \beta-5\right) e^{\left(-\frac{21}{\lambda_{i}}\right)}+0.0068 \lambda
$$

Where the tip speed ratio $\lambda$ and $\lambda_{i}$ are given by:

$$
\begin{aligned}
& \lambda=\frac{\Omega_{t} R}{V} \\
& \frac{1}{\lambda_{i}}=\frac{1}{\lambda+0.08 \beta}-\frac{0.035}{1+\beta^{3}}
\end{aligned}
$$

The mechanical energy conversion process is given by the fundamental principle of the dynamics [4,10]:

$$
J \frac{d \Omega_{g}}{d t}=T_{g}-T_{e m}-f_{v} \Omega_{g}
$$

Where $T_{e m}$ and $T_{g}$ are the electromagnetic and the mechanical torque of generator, $J$ is the total moment of inertia, $f_{v}$ is the viscous friction coefficient and $\Omega_{g}$ is the mechanical speed of DFIG. 


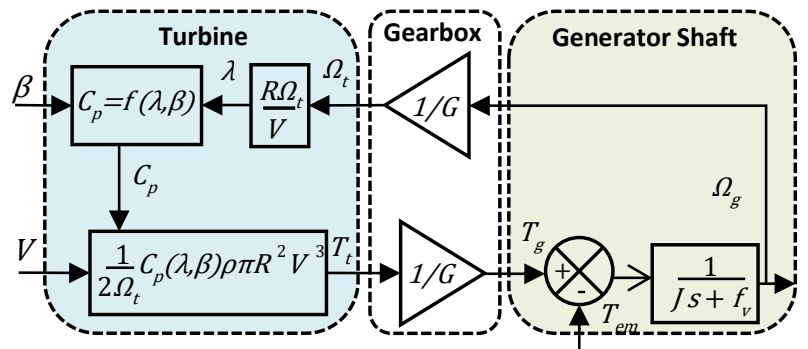

Figure. 2 Model of the wind turbine converter

\subsection{DFIG modeling}

The Park model of the DFIG is presented by the following equations [4,11,13-14].

The stator and rotor voltages of DFIG:

$$
\left\{\begin{array}{l}
V_{s d}=R_{s} I_{s d}+\frac{d \phi_{s d}}{d t}-\omega_{s} \phi_{s q} \\
V_{s q}=R_{s} I_{s q}+\frac{d \phi_{s q}}{d t}+\omega_{s} \phi_{s d} \\
V_{r d}=R_{r} I_{r d}+\frac{d \phi_{r d}}{d t}-\omega_{r} \phi_{r q} \\
V_{r q}=R_{r} I_{r q}+\frac{d \phi_{r q}}{d t}+\omega_{r} \phi_{r d}
\end{array}\right.
$$

The stator and rotor flux linkages:

$$
\left\{\begin{array}{l}
\phi_{s d}=L_{s} I_{s d}+L_{m} I_{r d} \\
\phi_{s q}=L_{s} I_{s q}+L_{m} I_{r q} \\
\phi_{r d}=L_{r} I_{r d}+L_{m} I_{s d} \\
\phi_{r q}=L_{r} I_{r q}+L_{m} I_{s q}
\end{array}\right.
$$

The electromagnetic torque is given by:

$$
T_{e m}=p \frac{M}{L_{s}}\left(\phi_{s d} I_{r q}-\phi_{s q} I_{r q}\right)
$$

The active and reactive powers:

$$
\left\{\begin{array}{l}
P_{s}=V_{s d} I_{s d}+V_{s q} I_{s q} \\
Q_{s}=V_{s q} I_{s d}-V_{s d} I_{s q}
\end{array}\right.
$$

In order to simplify the equations of the DFIG, we have chosen a stator flux constant and aligned along the $d$-axis of the Park reference [11]. By adopting the hypothesis of a stator resistance $R_{S}$ neglected [4,12], the electrical equations of the DFIG model will become as follow:

Thus

$$
\phi_{s d}=\phi_{s} \quad \phi_{s q}=0
$$

$$
V_{s d}=0 \quad V_{s q}=V_{s}=\phi_{s} \omega_{s}
$$

Under this assumption, the expressions of the rotor voltages as function of the rotor currents and the stator power can be expressed by [4]:

$$
\begin{gathered}
\left\{\begin{array}{l}
V_{r d}=R_{r} I_{r d}+L_{r} \sigma \frac{d I_{d r}}{d t}-g \omega_{s} L_{r} \sigma I_{r q} \\
V_{r q}=R_{r} I_{r q}+L_{r} \sigma \frac{d I_{r q}}{d t}-g \omega_{s} L_{r} \sigma I_{r d}+g \frac{V_{s} M}{L_{s}}
\end{array}\right. \\
\text { Where: } \quad \sigma=1-\frac{M^{2}}{L_{s} L_{r}}
\end{gathered}
$$

And:

$$
\left\{\begin{array}{l}
P_{s}=-V_{s} \frac{M}{L_{s}} I_{r q} \\
Q_{s}=-V_{s} \frac{M}{L_{s}} I_{r d}+\frac{V_{s}^{2}}{L_{s} \omega_{s}} \\
T_{e m}=-p \frac{M}{L_{s}} \phi_{s} I_{r q}
\end{array}\right.
$$

\subsection{Modeling of the PWM converters}

The back to back converter model, controlled by the PWM control, is expressed as follow [10]:

$$
\left[\begin{array}{l}
v_{r a} \\
v_{r b} \\
v_{r c}
\end{array}\right]=\frac{v_{d c}}{3}\left[\begin{array}{rrr}
2 & -1 & -1 \\
-1 & 2 & -1 \\
-1 & -1 & 2
\end{array}\right]\left[\begin{array}{l}
S_{a} \\
S_{b} \\
S_{c}
\end{array}\right]
$$

Where $\left(v_{r a}, v_{r b}, v_{r c}\right)$ and $\left(S_{a}, S_{b}, S_{c}\right)$ are respectively the output voltages and the switch states of the inverter.

The output current in the rotor side converter RSC side DC link is given by:

$$
I_{r m}=S_{a} I_{r 1}+S_{b} I_{r 2}+S_{c} I_{r 3}
$$

\subsection{Grid filter model}

The electrical voltages of the grid filter are given by the following equations [15]:

$$
\left\{\begin{array}{c}
V_{m d}=R_{f} i_{f d}+L_{f} \frac{d i_{f d}}{d t}+\omega_{s} L_{f} i_{f q}+V_{g d} \\
V_{m q}=R_{f} i_{f q}+L_{f} \frac{d i_{f q}}{d t}-\omega_{s} L_{f} i_{f d}+V_{g q}
\end{array}\right.
$$

By aligning grid voltage along q-axis position, the active and reactive power flow between the grid and the grid side converter GSC is given by [14]:

$$
\begin{aligned}
& V_{g d}=0 \\
& \left\{\begin{array}{l}
P_{g}=V_{s} I_{g q} \\
Q_{g}=-V_{s} I_{g d}
\end{array}\right.
\end{aligned}
$$

\subsection{Modeling of DC link}

By neglecting the losses in the converters, the DC link voltage model is given as [15]:

$$
P_{d c}=C V_{d c} \frac{d V_{d c}}{d t}=P_{r}-P_{g}
$$


Thus:

$$
\left\{\begin{array}{l}
P_{r}=V_{d c} I_{r m} \\
P_{g}=P_{f}=V_{s} I_{f q} \\
Q_{g}=Q_{f}=-V_{s} I_{f d}
\end{array}\right.
$$

\section{Design of control strategies}

\subsection{Design of MPPT control strategy}

The Maximum Power Point Tracking control (MPPT) impose a reference electromagnetic torque so as to allow the DFIG tracks the optimal wind turbine speed for maximum energy capture from the wind (Fig. 3). Therefore, the speed ratio of the wind turbine $\lambda$ is maintained at its optimum value $\lambda_{\text {opt }}$ and the power coefficient at its maximum value $C_{p \max }$.

The Fig. 4 shows that the power coefficient $C_{p}$ reaches its maximum value $C_{p m a x}=0.4728$ for a speed ratio $\lambda_{\text {opt }}=8.376$ and $\beta=0^{\circ}$.

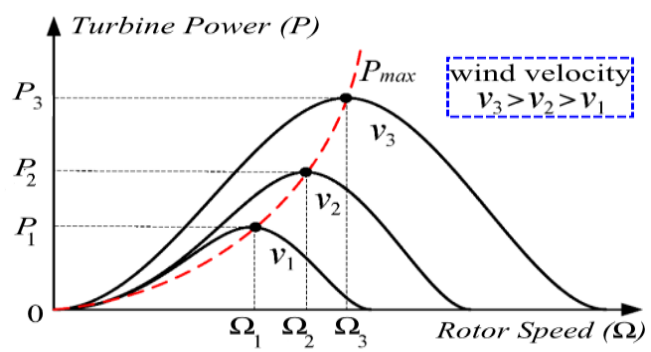

Figure.3 Wind turbine characteristic with MPPT

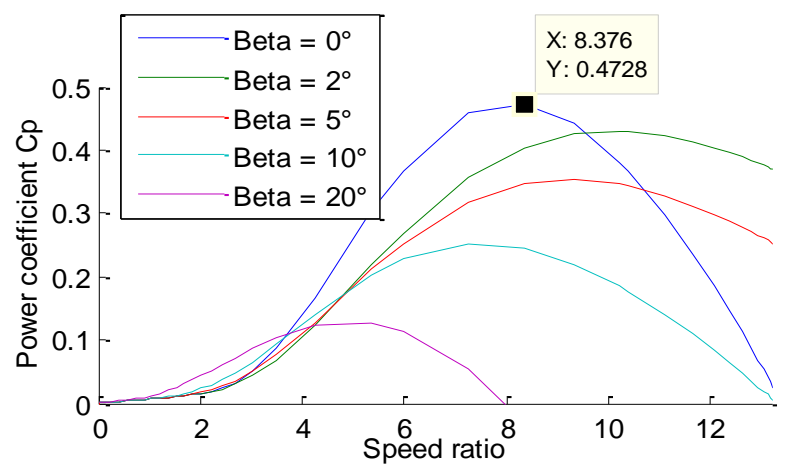

Figure.4 Power coefficient $\left(C_{p}\right)$ in function of speed ratio $(\lambda)$ and pitch angle $(\beta)$

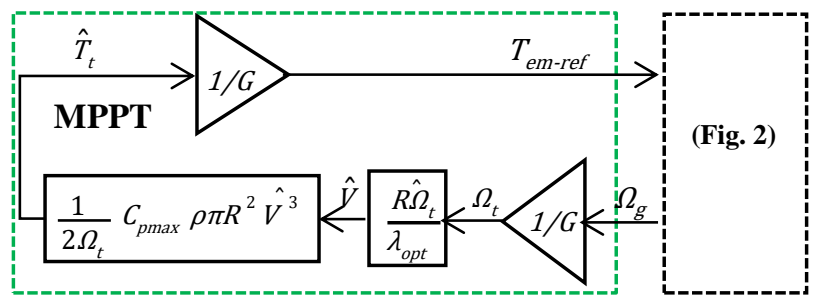

Figure.5 Model with the MPPT without speed control

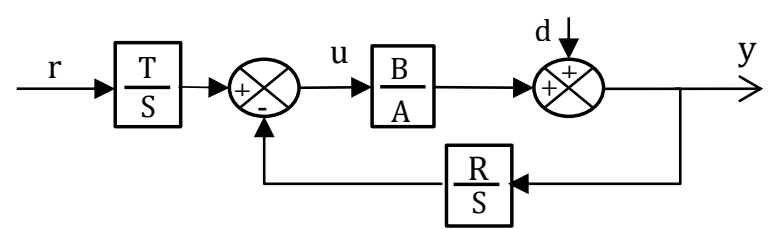

Figure.6 The general Structure of RST controller

We are interested in MPPT strategy without control of the mechanical speed (Fig. 5) because it is difficult to have an exact measurement of the wind speed [10].

\subsection{Design of RST controller}

The RST regulator is a linear control device composed of three polynomials $\mathrm{R}(\mathrm{s}), \mathrm{S}(\mathrm{s})$ and $\mathrm{T}(\mathrm{s})$ to be determined in order to obtain an effective control, in the single-variable context, it is the regulators which offer the greatest flexibility of use. The general structure of the RST controller is depicted in Fig. 6 [3,4,6].

Where $B / A$ is the system transfer function, $r$ is the reference input and $d$ is the total disturbance.

The RST controller is based on the pole placement theory which consists in specifying an arbitrary stability polynomial $D(s)$. To determine the polynomials $R(s)$ and $S(s)$, we have to solve the following equation called Bezout equation $[4,16,17]$.

$$
\left\{\begin{array}{l}
D(s)=A(s) \cdot S(s)+B(s) \cdot R(s)=C(s) \cdot F(s) \\
D(s)=\mathrm{s}^{3}-\left(\mathrm{s}_{\mathrm{c}}+2 \mathrm{~s}_{\mathrm{f}}\right) \mathrm{s}^{2}+\left(\mathrm{s}_{\mathrm{f}}^{2}+2 \mathrm{~s}_{c} \mathrm{~s}_{\mathrm{f}}\right) \mathrm{s}-\mathrm{s}_{\mathrm{c}} \mathrm{s}_{\mathrm{f}}^{2}
\end{array}\right.
$$

Where:

$$
\left\{\begin{array}{l}
A(s)=a_{1} s+a_{0} \\
B(s)=b_{0} \\
R(s)=r_{1} s+r_{0} \\
S(s)=s_{2} s^{2}+s_{1} s+s_{0} \\
D(s)=d_{3} s^{3}+d_{2} s^{2}+d_{1} s+d_{0} \\
C(s)=\left(s-s_{c}\right) \\
F(s)=\left(s-s_{f}\right)^{2} \\
T(s)=T_{0}
\end{array}\right.
$$

Where, $s_{c}$ and $s_{f}$ are respectively the pole of the control polynomial $C(s)$ and the double pole of the filtering polynomial $F(s)$.

The control pole allows accelerating the system, it is chosen greater than the pole $s_{A}$ of the polynomial $A$, and in order to enhance the regulator robustness, the pole $s_{f}$ is chosen greater than $s_{c}[4,6]$.

Generally we chose:

$$
s_{c}=5 s_{A}=-5 \frac{a_{0}}{a_{1}}
$$




$$
\text { And: } \quad s_{f}=3 s_{c}=15 s_{A}=-15 \frac{a_{0}}{a_{1}}
$$

The coefficients of the polynomials $R(s)$ and $S(s)$ can be calculated by the following matrix called Sylvester matrix [4]:

$$
\left[\begin{array}{l}
d_{3} \\
d_{2} \\
d_{1} \\
d_{0}
\end{array}\right]=\left[\begin{array}{cccc}
a_{1} & 0 & 0 & 0 \\
0 & a_{1} & 0 & 0 \\
0 & a_{0} & b_{0} & 0 \\
0 & 0 & 0 & b_{0}
\end{array}\right]\left[\begin{array}{l}
s_{2} \\
s_{1} \\
r_{1} \\
r_{0}
\end{array}\right]
$$

From the Eq. (22), Eq. (23) and Eq. (26) we deduce the RST controller parameters:

$$
\left\{\begin{array}{l}
d_{3}=1=a_{1} s_{2} \\
d_{2}=-s_{c}-2 s_{f}=a_{1} s_{1} \\
d_{1}=s_{f}^{2}+2 s_{c} s_{f}=a_{0} s_{1}+b_{0} r_{1} \\
d_{0}=-s_{c} s_{f}^{2}=b_{0} r_{0}
\end{array}\right.
$$

Thus, the parameters of RST controller [4,6] are:

$$
\left\{\begin{array}{l}
s_{2}=\frac{1}{a_{1}} \\
s_{1}=\frac{35 a_{0}}{a_{1}^{2}} \\
s_{0}=0 \\
r_{1}=\frac{340 a_{0}^{2}}{b_{0} a_{1}^{2}} \\
r_{0}=T_{0}=\frac{1125 a_{0}^{3}}{b_{0} a_{1}^{3}}
\end{array}\right.
$$

\subsection{Design of ADRC controller}

Active disturbance rejection control (ADRC) is a new robust command based on the state observer called extended state observer (ESO) allows estimating any unexpected disturbance.

We illustrate the principle of the linear ADRC controller for a first order system with single input $\mathrm{u}$ and single output y $[4,8,18]$.

$$
\frac{d y}{d t}=f(y, d, t)+b_{0} u
$$

Where $f$ is the total disturbance, $d$ is the external disturbance and $b_{0}$ is the known parameter of the system.

By considering two state variables as $Z=\left[z_{1}, z_{2}\right]^{T}=[y, f]^{T}$, the Eq. (29) can be expressed by the following state space $[7,18,19]$ :

$$
\left\{\begin{array}{l}
\dot{z}_{1}=z_{2}+b_{0} u \\
\dot{z}_{2}=\dot{f}=h \\
y=z_{1}
\end{array}\right.
$$

We put $h=\dot{f}$

Eq. (30) can be transformed in matrix equation as:

$$
\left\{\begin{array}{l}
\dot{Z}=A Z+B b_{0} u+D h \\
y=C Z
\end{array}\right.
$$

Where:

$A=\left[\begin{array}{ll}0 & 1 \\ 0 & 0\end{array}\right], \quad B=\left[\begin{array}{l}1 \\ 0\end{array}\right], \quad C=\left[\begin{array}{l}1 \\ 0\end{array}\right]^{T}, \quad D=\left[\begin{array}{l}0 \\ 1\end{array}\right]$

The total disturbance $f$ is estimated by a linear extended state observer (ESO) which it is designed as follow:

$$
\left\{\begin{array}{l}
\dot{Z}=A Z+B b_{0} u+D(y-\hat{y}) \\
\hat{y}=C Z
\end{array}\right.
$$

Where $D=\left[\beta_{1}, \beta_{2}\right]^{T}$ is the gain of the observer $z_{1}$ and $z_{2}$ are respectively the estimation of $y$ and $f$ which represent the output of the ESO.

Thus, the system of equations of the extended state observer is given as follow [4,20].

$$
\left\{\begin{array}{l}
\dot{\hat{z}}_{1}=\hat{z}_{2}+\beta_{1}\left(y-\hat{z}_{1}\right)+b_{0} u \\
\dot{\hat{z}}_{2}=\beta_{2}\left(y-\hat{z}_{1}\right)
\end{array}\right.
$$

By using the bandwidth parameterization technic, the observer gains are choosed in the condition of all eigenvalues of the matrix $(A-L C)$ are placed at $-\omega_{0}[6-7]$.

$$
\left\{\begin{array}{l}
\beta_{1}=-2 \omega_{0} \\
\beta_{2}=\omega_{0}^{2}
\end{array}\right.
$$

Where $\omega_{0}$ is the bandwidth of the observer ESO, it is defined by the technique of placement of the poles.

The control law in first-order ADRC $[19,20]$ is:

$$
\begin{aligned}
& u_{0}=K_{p}\left(r-\hat{z}_{1}\right) \\
& u=\frac{u_{0}-\hat{z}_{2}}{b_{0}}
\end{aligned}
$$

Where, $K_{P}$ is the control parameter of the linear $\mathrm{ADRC}$ and $r$ is the reference input signal [4, 20]. Generally:

$$
\left\{\begin{array}{l}
K_{p}=\omega_{c} \\
\omega_{0}=3 \sim 7 \omega_{c}
\end{array}\right.
$$

Where $\omega_{c}$ is the controller bandwidth.

Therefore, the linear ADRC can be controlled by a single parameter $K_{P}$. This simplification of this control strategy meanwhile highly promotes the convenience of application in industrial field.

Fig. 7 shows the general structure of the linear ADRC for a first order system $[19,20]$. 


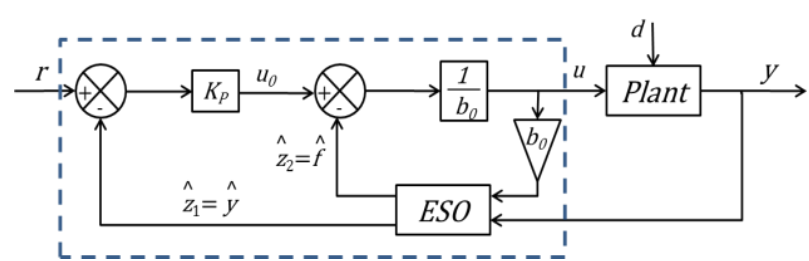

Figure.7 The general Structure of ADRC controller

\section{Control of DFIG}

\subsection{Control of the rotor side converter by using} RST controller

The transfer function of our system is:

$$
\frac{B(s)}{A(s)}=\frac{M V_{S}}{L_{S} R_{r}+s L_{s} L_{r} \sigma}
$$

From the Eq. (22), we obtain the control parameters:

$$
\left\{\begin{array}{l}
s_{2}=\frac{1}{L_{s} L_{r} \sigma} \\
s_{1}=\frac{35 R_{r}}{L_{S}\left(L_{r} \sigma\right)^{2}} \quad ; s_{0}=0 \\
r_{1}=\frac{340 R_{r}^{2}}{M V_{S}\left(L_{r} \sigma\right)^{2}} \\
r_{0}=T_{0}=\frac{1125 R_{r}^{3}}{M V_{S}\left(L_{r} \sigma\right)^{3}}
\end{array}\right.
$$

The Fig. 8 depicts the control of the stator active and reactive powers produced by the DFIG through controlling the RSC using RST control.

\subsection{Control of the rotor side converter by using ADRC controller}

The rotor currents in Eq. (12) can be written as:

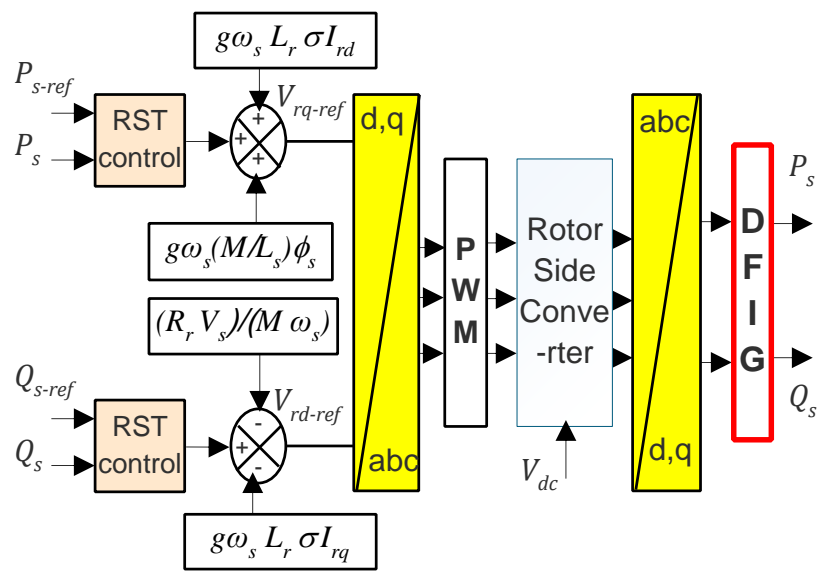

Figure.8 Block Diagram of RST control of DFIG $\left\{\begin{array}{l}\frac{d I_{r d}}{d t}=-\frac{R_{r}}{\sigma L_{r}} I_{r d}+\omega_{r} I_{r q}+\frac{1}{\sigma L_{r}} V_{r d} \\ \frac{d I_{r q}}{d t}=-\frac{R_{r}}{\sigma L_{r}} I_{r q}-\omega_{r} I_{r d}-\omega_{r} \frac{M}{\sigma L_{r} L_{s}} \phi_{s q}+\frac{1}{\sigma L_{r}} V_{r q}\end{array}\right.$

This equation can be written as:

$\left\{\begin{array}{l}\frac{d I_{r d}}{d t}=f\left(I_{r d}, d, t\right)+b_{0} u(t) \\ \frac{d I_{r q}}{d t}=f\left(I_{r q}, d, t\right)+b_{0} u(t)\end{array}\right.$

Where:

$\left\{\begin{array}{c}f\left(I_{r d}, d, t\right)=-\frac{R_{r}}{\sigma L_{r}} I_{r d}+\omega_{r} I_{r q} \\ u(t)=V_{r d} \quad \text { and } \quad b_{0}=\frac{1}{\sigma L_{r}}\end{array}\right.$

$\left\{\begin{array}{c}f\left(I_{r q}, d, t\right)=-\frac{R_{r}}{\sigma L_{r}} I_{r q}-\omega_{r} I_{r d}-\omega_{r} \frac{M}{\sigma L_{r} L_{s}} \phi_{s q} \\ u(t)=V_{r q} \quad \text { and } \quad b_{0}=\frac{1}{\sigma L_{r}}\end{array}\right.$

The Fig. 9 depicts the control of the stator active and reactive powers produced by the DFIG through controlling the RSC using the linear ADRC control.

\section{Regulation of DC bus voltage}

\subsection{Regulation of DC bus voltage with RST}

The DC bus voltage control allows giving the reference quadratic current of the grid filter $I_{f q-r e f}$. The transfer function of DC bus is:

$$
\frac{B(s)}{A(s)}=\frac{1}{s C}
$$

From the Eq. (22), the RST control parameters are:

$$
\left\{\begin{array}{l}
s_{2}=\frac{1}{c} \\
s_{1}=s_{0}=r_{1}=r_{0}=T_{0}=0
\end{array}\right.
$$

The Fig. 10 depicts the control of DC link voltage by using RST controller.

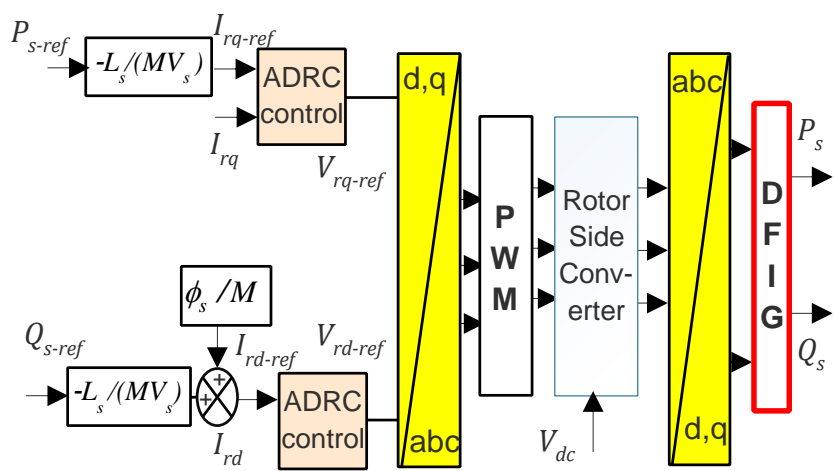

Figure.9 Block diagram of linear ADRC control of DFIG 


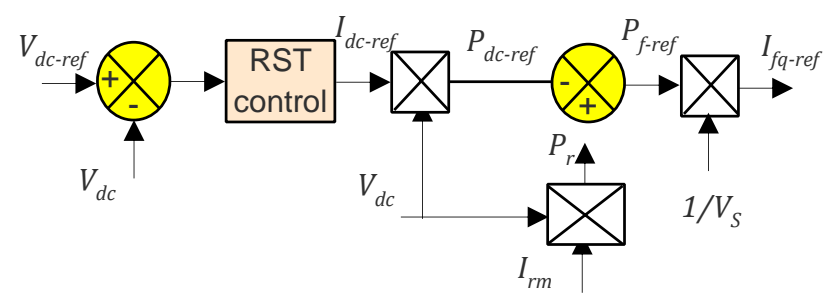

Figure.10 DC link voltage control with RST controller

\subsection{Regulation of DC bus voltage with ADRC}

The Eq. (20) can be written as follows:

$$
\frac{d V_{d c}{ }^{2}}{d t}=\frac{2}{C} V_{d c} I_{r m}-\frac{2}{C} V_{s} I_{f q}
$$

This equation is given by the canonical form of the ADRC as follows:

$$
\frac{d V_{d c^{2}}}{d t}=f\left(V_{d c}^{2}, d, t\right)+b_{0} u(t)
$$

Where:

$$
\left\{\begin{array}{l}
f\left(V_{d c}{ }^{2}, d, t\right)=\frac{2}{c} V_{d c} I_{r m} \\
u(t)=I_{f q} \text { and } b_{0}=-\frac{2}{c} V_{s}
\end{array}\right.
$$

The Fig. 11 represents block diagram of the of the linear ADRC control of DC link voltage.

\section{Control of grid filter}

\subsection{Control of the grid side converter with RST}

The transfer function of the grid filter is:

$$
\frac{B(s)}{A(s)}=\frac{1}{R_{f}+s L_{f}}
$$

From Eq. (22), we deduce the parameters of control:

$$
\left\{\begin{array}{l}
s_{2}=\frac{1}{L_{f}} ; \quad S_{1}=\frac{35 R_{f}}{L_{f}^{2}} ; \quad S_{0}=0 \\
r_{1}=\frac{340 R_{f}^{2}}{L_{f}^{2}} ; \quad r_{0}=T_{0}=\frac{1125 R_{f}^{3}}{L_{f}^{3}}
\end{array}\right.
$$

The Fig. 12 depicts the control of the grid filter by using RST controller.

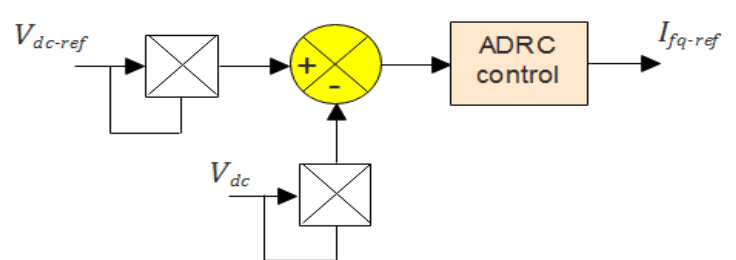

Figure.11 DC link voltage control with ADRC controller

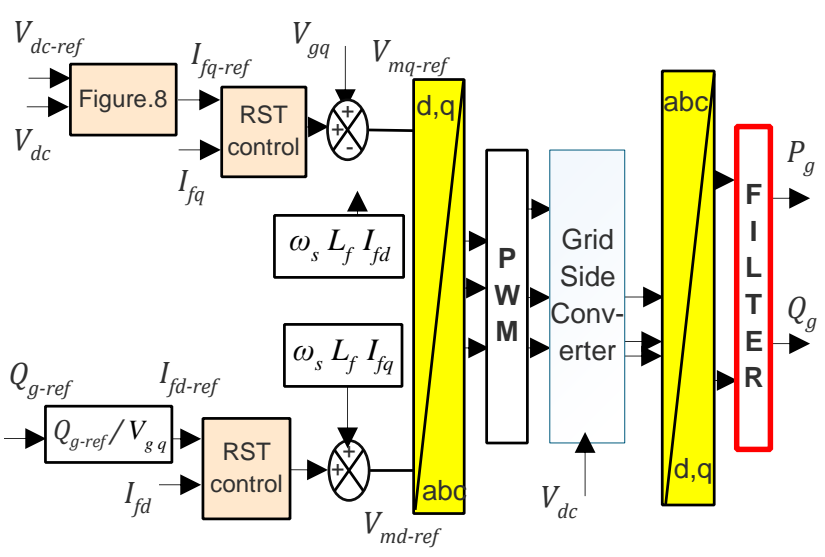

Figure.12 Block diagram of grid filter control with RST

\subsection{Control of grid side converter with ADRC}

From Eq. (17), the grid currents can be written as follows:

$$
\left\{\begin{array}{l}
\frac{d I_{f d}}{d t}=-\frac{R_{f}}{L_{f}} I_{f d}+\omega_{s} I_{f q}-\frac{1}{L_{f}} V_{g d}+\frac{1}{L_{f}} V_{m d} \\
\frac{d I_{f q}}{d t}=-\frac{R_{f}}{L_{f}} I_{f q}-\omega_{s} I_{f d}-\frac{1}{L_{f}} V_{g q}+\frac{1}{L_{f}} V_{m q}
\end{array}\right.
$$

These equations can be written as follows:

$$
\left\{\begin{array}{l}
\frac{d I_{f d}}{d t}=f\left(I_{f d}, d, t\right)+b_{0} u(t) \\
\frac{d I_{f q}}{d t}=f\left(I_{f q}, d, t\right)+b_{0} u(t)
\end{array}\right.
$$

Where:

$$
\left\{\begin{array}{c}
f\left(I_{f d}, d, t\right)=-\frac{R_{f}}{L_{f}} I_{f d}+\omega_{s} I_{f q}-\frac{1}{L_{f}} V_{g d} \\
u(t)=V_{m d} \quad \text { and } \quad b_{0}=\frac{1}{L_{f}}
\end{array}\right.
$$

$$
\left\{\begin{array}{l}
f\left(I_{f d}, d, t\right)=-\frac{R_{f}}{L_{f}} I_{f q}-\omega_{s} I_{f d}-\frac{1}{L_{f}} V_{g q} \\
u(t)=V_{m q} \quad \text { and } \quad b_{0}=\frac{1}{L_{f}}
\end{array}\right.
$$

The Fig. 13 represents the block diagram of power control of grid filter with ADRC controller.

\section{Results of simulation and discussion}

The simulation has achieved with MATLAB/Simulink software and the parameters values of the DFIG, the wind turbine, DC bus, the grid filter and the both controllers are given in Tables 2 and 3 .

Fig. 14 shows the variation of the wind speed applied to the wind turbine, which varies between $5 \mathrm{~m} / \mathrm{s}$ and $12 \mathrm{~m} / \mathrm{s}$. 


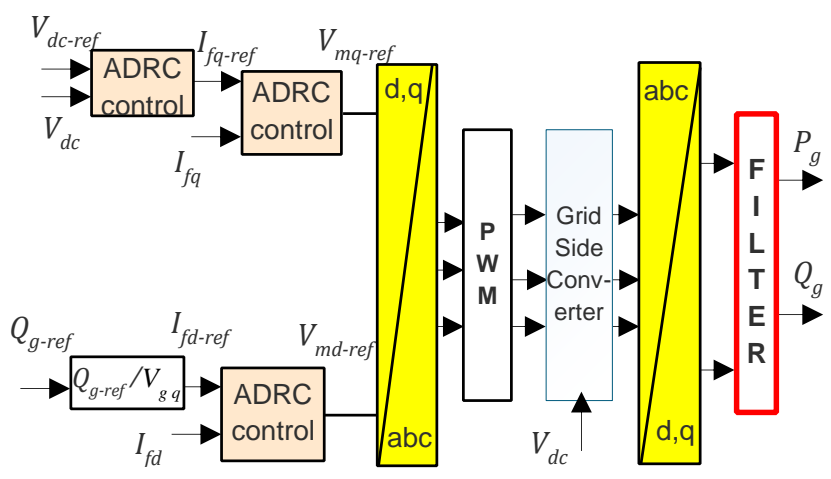

Figure.13 Block diagram of grid filter control by ADRC

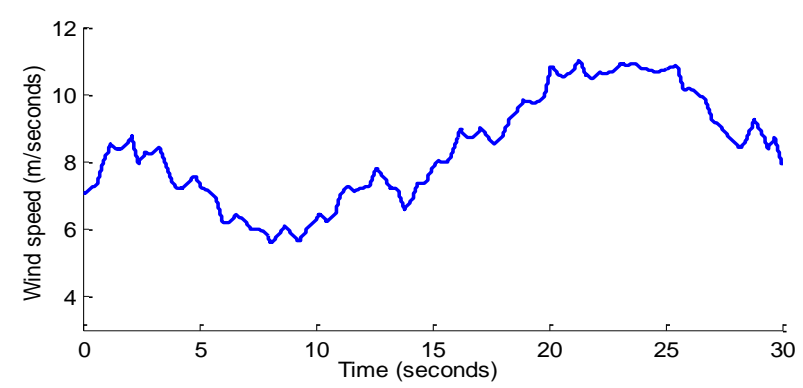

Figure.14 Wind speed profile

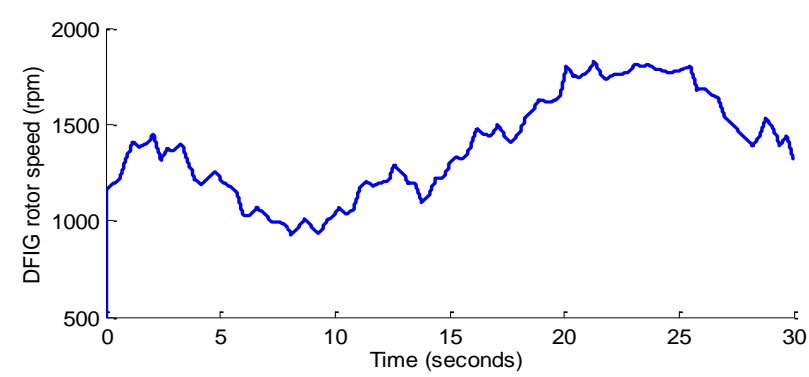

Figure.15 Mechanical rotor speed of DFIG

From Fig. 14 and Fig. 15, we can observe that the turbine has a good adaptation to the wind variation thanks to the MPPT strategy.

\subsection{Reference tracking test}

The stator power reference is proportional to the speed of the generator obtained thanks to the MPPT. And the reactive power reference is chosen equal to zero to have a unit power factor.

The Fig. 16 and Fig. 17 present respectively the simulation results corresponding to active and reactive powers of stator obtained by using RST and linear ADRC controllers. These DFIG output powers converge and track exactly their references. But we can observe that there are some differences between the results obtained by the both controllers: The settling time for the ADRC controller $(60 \mathrm{~ms})$ is lower than the settling time of the RST controller $(10 \mathrm{~ms})$ (case of the reactive power). In addition, in the steady state regime the responses obtained with the ADRC control are more precise and have a very less static error and (case of the active power) compared to RST control.

The Fig. 18 and Fig. 19 illustrate respectively the simulation results corresponding to reactive power of the grid and the DC bus voltage controlled through RST and linear ADRC controllers. We can observe that the DC bus voltage is maintained to its reference by using these both controllers but the static error, the response time and the overshoot obtained by ADRC still very low compared to the RST. In addition, the reactive power is kept at zero according to its reference in order to maintain a unit power factor but always the response is more accurate with ADRC.

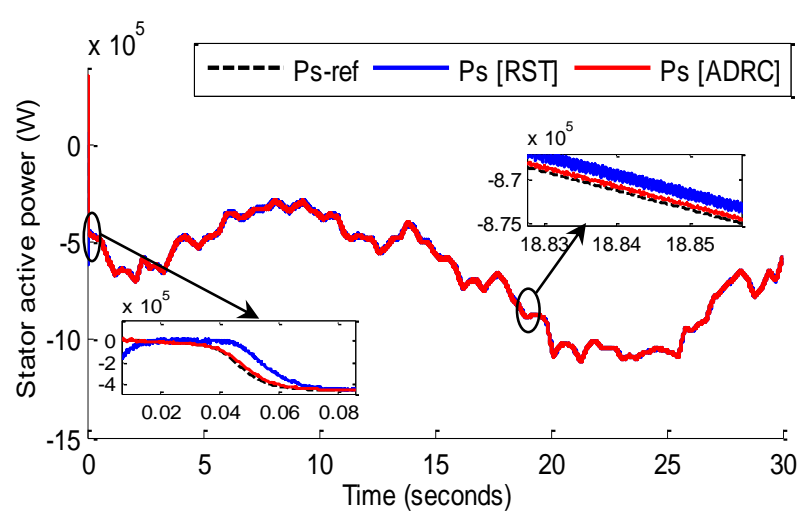

Figure.16 Stator active power of DFIG

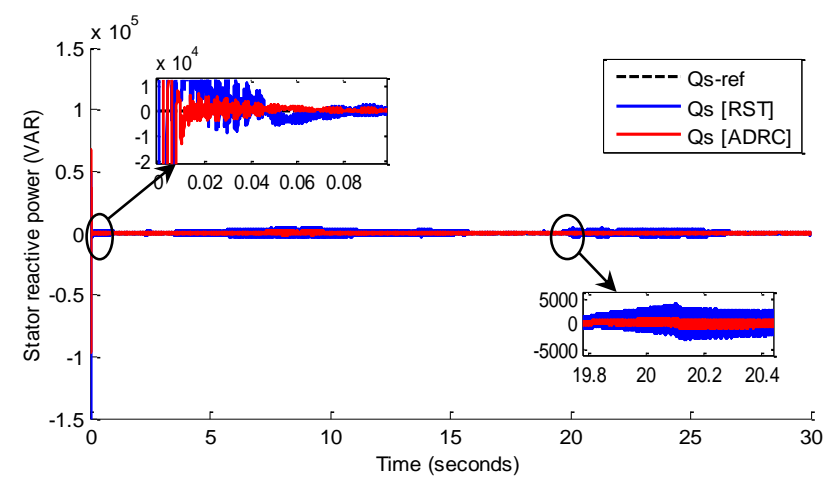

Figure.17 Stator reactive power of DFIG

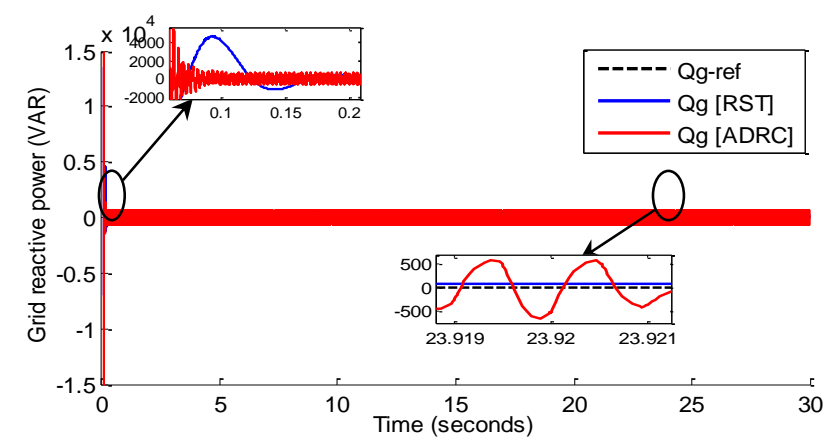

Figure.18 Reactive power of the grid 


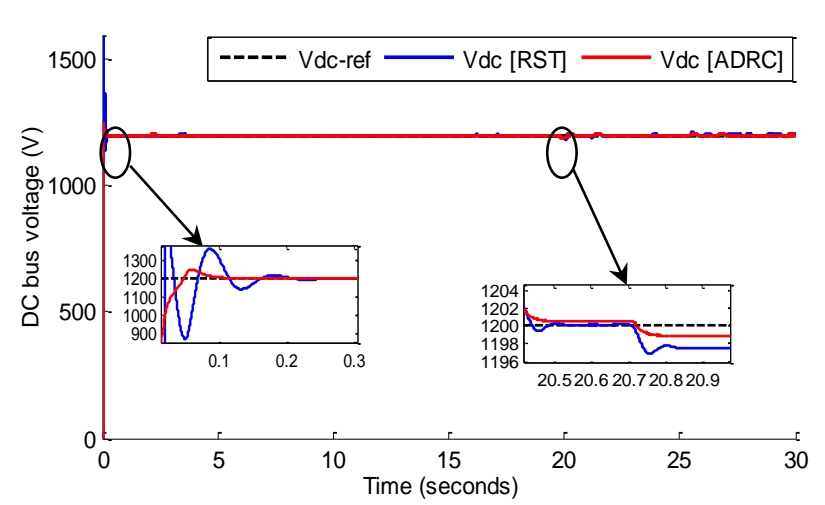

Figure.19 DC bus Voltage

\subsection{Robustness test}

Fig. 20 to Fig. 23 illustrate the responses of the powers of DFIG with variation, respectively, of the value of the rotor resistance by $30 \%$ and the value of the rotor inductance by $50 \%$. The obtained results show that the robustness is ensured by these two controllers, but the responses of the ADRC controller are better than the RST controller.

Fig. 24 shows that the response time of DC link voltage with RST controller increased with increasing the capacitance value of the DC link capacitor by $40 \%$. In case of the increase of the grid filter resistance value by $40 \%$ (Fig. 25), we observe that the response of the grid reactive power obtained by ADRC presents a neglected static error compared to RST. Therefore, from these results, we can observe that the performance of the ADRC controller is better than the RST controller.

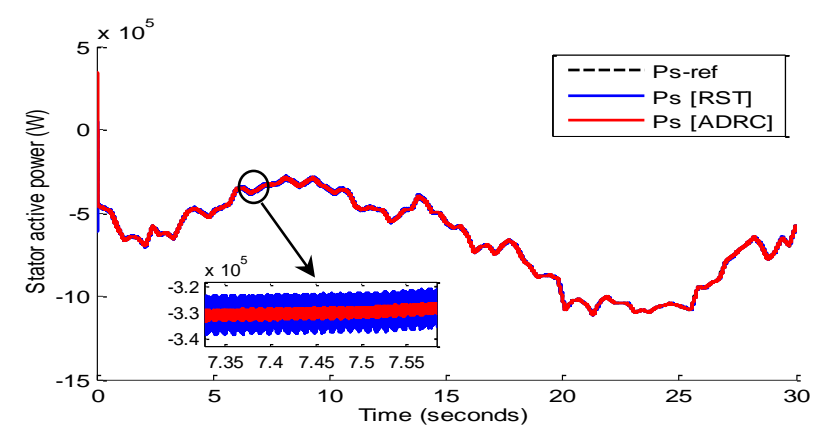

Figure.20 Stator active power for $130 \% R_{r}$

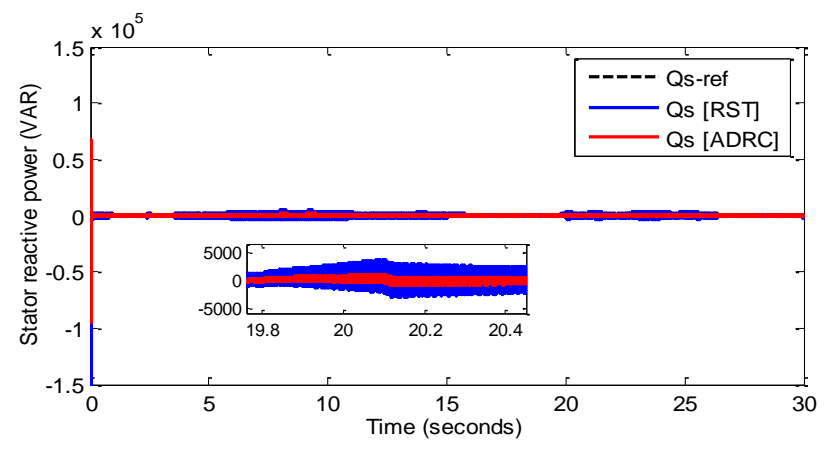

Figure.21 Stator reactive power for $130 \% R_{r}$

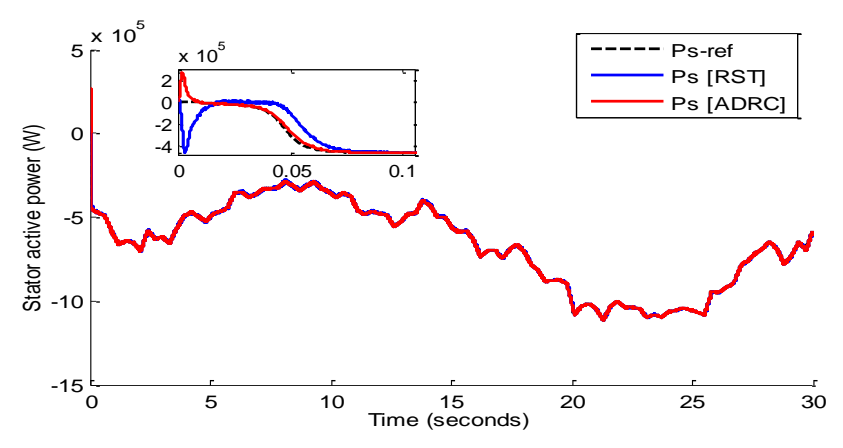

Figure.22 Stator active power for $150 \% L_{r}$

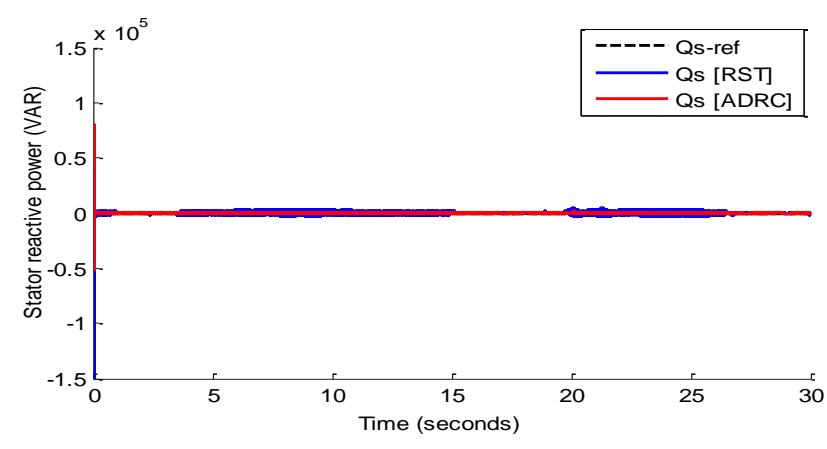

Figure.23 Stator reactive power for $150 \% L_{r}$

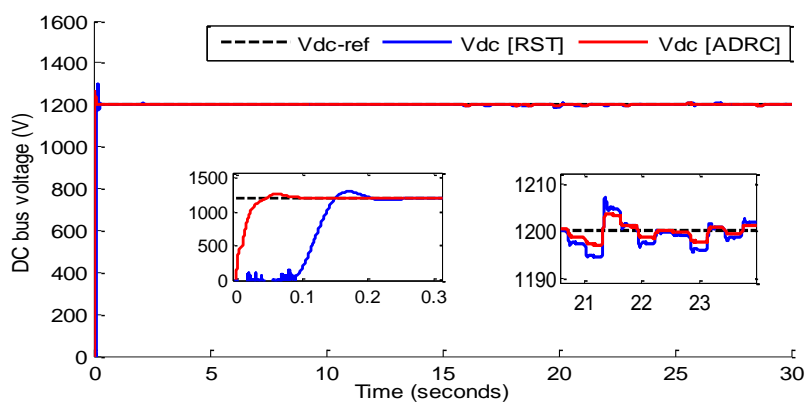

Figure.24 DC link voltage for $140 \% C$

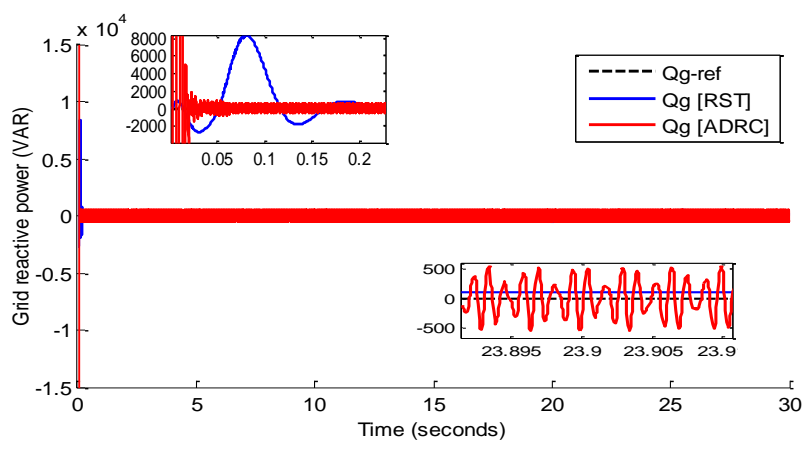

Figure. 25 Reactive power of the grid for $140 \% R_{f}$

\section{Conclusion}

In this work, we have presented the modeling and control of the wind turbine system based on doubly fed induction generator which the stator is directly connected to the electrical grid and the rotor 
also connected through back-to-back converter. The aim of the new ADRC control is to improve system performance by better tracking the maximum power point of the wind turbine chain, maintain DC bus voltage at constant value and to ensure a unitary power factor whatever the wind speed and with significant advantages compared to other strategies applied in the literature.

Considering the simulation results, the active disturbance rejection controller (ADRC) achieves very good performance and efficiency, in term of reference tracking and in term of robustness, higher to those obtained with the RST controller, which achieve the best maximum power point tracking, In addition, The ADRC controller has a single setting parameter which makes it easy to implement.

Table 3. Parameters of DFIG

\begin{tabular}{|c|c|}
\hline Parameter & Value \\
\hline Rated power & $P_{n}=1.5 \mathrm{MW}$ \\
\hline Number of pole pairs & $p=2$ \\
\hline Rated stator voltage & $398 / 690 \mathrm{~V}$ \\
\hline Stator resistance & $R_{s}=0.012 \Omega$ \\
\hline Rotor resistance & $R_{r}=0.021 \Omega$ \\
\hline Stator inductance & $L_{s}=0.0137 \mathrm{H}$ \\
\hline Rotor inductance & $L_{r}=0.01367 \mathrm{H}$ \\
\hline Mutual inductance & $M=0.0135 \mathrm{H}$ \\
\hline Nominal frequency & $f=50 \mathrm{~Hz}$ \\
\hline DC bus voltage & $V_{d c}=1200 \mathrm{~V}$ \\
\hline
\end{tabular}

Table 4. Parameters of turbine

\begin{tabular}{|c|c|}
\hline Parameter & Value \\
\hline Density of ajir & $\rho=1.225 \mathrm{~kg} / \mathrm{m}^{3}$ \\
\hline Damping coefficient & $f_{v}=0.0024$ \\
\hline Moment of inertia & $J=10 \mathrm{~kg} \cdot \mathrm{m}^{2}$ \\
\hline Turbine diameter & $D=70.5 \mathrm{~m}$ \\
\hline Gain of the multiplier & $G=90$ \\
\hline
\end{tabular}

Table 3. Parameters of grid filter

\begin{tabular}{|c|c|}
\hline Parameter & Value \\
\hline Inductance of the filter & $L_{f}=2 \mathrm{mH}$ \\
\hline Resistance of the filter & $R_{f}=5 \mathrm{mH}$ \\
\hline DC link capacitor & $C=4400 \mu \mathrm{F}$ \\
\hline
\end{tabular}

Table 5. Parameters of ADRC Controller

\begin{tabular}{|c|c|c|c|}
\hline Parameter & $\begin{array}{c}\text { DFIG } \\
\text { control }\end{array}$ & $\begin{array}{c}\text { Grid } \\
\text { filter }\end{array}$ & $\begin{array}{c}\text { DC } \\
\text { link }\end{array}$ \\
\hline Control parameter $K_{p}$ & 400 & 130 & 120 \\
\hline $\begin{array}{c}\text { Bandwidth of ESO } \\
\omega_{0}=5 . \omega_{\mathrm{C}}\end{array}$ & 2000 & 650 & 600 \\
\hline $\begin{array}{c}\text { Parameters of ESO } \beta_{1} \\
\beta_{2}\end{array}$ & $\begin{array}{c}4000 \\
4000000\end{array}$ & $\begin{array}{c}1300 \\
422500\end{array}$ & $\begin{array}{c}1200 \\
360000\end{array}$ \\
\hline
\end{tabular}

In our future work, the ADRC control strategy will be used to control of the wind turbine based on DFIG connected to the grid in primary frequency regulation in order to solve the problem of imbalance between production and consumption.

\section{References}

[1] Z. Chen, J. M. Guerrero, and F. Blaabjerg, "A Review of the State of the Art of Power Electronics for Wind Turbines", IEEE Transactions on Power Electronics, Vol.24, No.8, pp.1859-1874, 2009.

[2] M. El Azzaoui, H. Mahmoudi, C. Ed-dahmani, and K. Boudaraia, "Comparing Performance of PI and Sliding Mode in Control of Grid Connected Doubly Fed Induction Generator", In: Proc. of IEEE International Renewable and Sustainable Energy Conference (IRSEC), pp.769-774, 2016.

[3] B. Hamane, M. L. Doumbia, M. Bouhamida, A. Draou, H. Chaoui, and M. Benghanem, "Comparative Study of PI, RST, Sliding Mode and Fuzzy Supervisory Controllers for DFIG based Wind Energy Conversion System", International Journal of Renewable Energy Research, Vol.5, No.4, pp.1174-1185, 2015.

[4] M. Chakib, A. Essadki, and T. Nasser, "A Comparative Study of PI, RST and ADRC Control Strategies of a Doubly Fed Induction Generator Based Wind Energy Conversion System", International Journal of Renewable Energy Research, Vol.8, No.2, pp.964-973, 2018.

[5] R. Madiouni, S. Bouallègue, J. Haggège, and P. Siarry, "Robust RST Control Design based on Multi-Objective Particle Swarm Optimization Approach", International Journal of Control, Automation and Systems, Vol.14, No.6, pp.1-11, 2016.

[6] B. Rached, M. Elharoussi, and E. Abdelmounim, "Control Strategies for DFIG based on Wind Energy Conversion System using RST and Fuzzy Logic Controllers", In: Proc. of International Conference of Computer Science and Renewable Energies (ICCSRE), pp.1-6, 2019.

[7] D. Li, Z. Wang, W. Yu, Q. Li, and Q. Jin, "Application of LADRC with Stability Region for a Hydrotreating Back-Flushing Process", Control Engineering Practice, Vol.79, pp.185194, 2018.

[8] X. Zhou, C. Yang, B. Zhao, L. Zhao, and Z. Zhu, "A High-Precision Control Scheme Based on Active Disturbance Rejection Control for a 
Three-Axis Inertially Stabilized Platform for Aerial Remote Sensing Applications", Hindawi Journal of Sensors, Vol.2018, pp.1-9, 2018.

[9] D. C. Phan, T. H. Trinh, "Application of Linear Quadratic Regulator to Control Directly Power for DFIG Wind Turbine", Journal of Electrical Systems, Vol.15, No.1, pp.42-52, 2019.

[10] Y. Ihedrane, C. El Bekkali, B. Bossoufi, and M. Bouderbala, "Modeling, Identification and Control Methods in Renewable Energy Systems", Chapter 5, Control of Power of a DFIG Generator with MPPT Technique for Wind Turbines Variable Speed, Springer Singapore, 2019.

[11] A. Merabet, H. Eshaft, A. A. Tanvir, "Powercurrent controller based sliding mode control for DFIG-wind energy conversion system", IET Renewable Power Generation, Vol.12, No.10, pp. 1155-1163, 2018.

[12] Y. Bakou, L. Saihi, K. Koussa, F. Ferroudji, K. Roumani, F. Meguellati, Y. Hammaoui, M. Abid, I. Yaichi, A. Aissaoui, "Design of Robust Control Based on $\mathrm{H} \infty$ Approach of DFIG for Wind Energy System", In: Proc. of 1st IEEE Global Power, Energy and Communication Conference, pp. 337-341, 2019.

[13] M. Y. Halyani, H. M. S. Firdaus, M. Zainon, E. Z. Ahmad and I. Norain, "Modelling and Simulation of a Wind Turbine with Doubly Fed Induction Generator in Full Load Operation", ARPN Journal of Engineering and Applied Sciences, Vol.13, No.1, pp.57-63, 2018.

[14] O. Belounis, and H. Labar, "Fuzzy Sliding Mode Controller of DFIG for Wind Energy Conversion", International Journal of Intelligent Engineering and Systems, Vol.10, No.2, pp.163-172, 2017.

[15] S. Kouadria, S. Belfedhal, Y. Messlem, E. Berkouk, "Study and Control of Wind Energy Conversion System (WECS) Based on the Doubly Fed Induction Generator (DFIG) Connected to the Grid", In: Proc. of IEEE International Conference on Ecological Vehicles and Renewable Energies (EVER), Monte-Carlo, Monaco, pp.1-7, 2014.

[16] M. Bendjedia, K. A. Tehrani, and Y. Azzouz, "Design of RST and Fractional order PID controllers for an Induction motor drive for Electric Vehicle Application", In: Proc. of 7th IET International Conference on Power Electronics, Machines and Drives (PEMD), pp.1-8, 2014.

[17] M. Dulau, S. E. Oltean, and A. V. Duka, "R-S$\mathrm{T}$ Conventional Controller Design for Slow Processes", In: Proc. of the 13th International
Conference on Engineering of Modern Electric Systems, pp.1-4, 2015.

[18] A. Benrabah, F. Khoucha, A. Raza and D. Xu, "A New Robust Control for Grid Connected Photovoltaic Systems Based on Active Disturbance Rejection Control", Journal of Electrical Systems, Vol.15, No.1, pp.81-95, 2019.

[19] N. Liu, X. Lyu, Y. Zhu and J. Fei, "Active Disturbance Rejection Control for Current Compensation of Active Power Filter", International Journal of Innovative Computing, Information and Control, Vol.12, No.2, pp.407418, 2016.

[20] Z. Lei, X. Sun, B. Xing, Y. Hu, and G. Jin, "Active Disturbance Rejection based MPPT Control for Wind Energy Conversion System under Uncertain Wind Velocity Changes", Journal of Renewable And Sustainable Energy, Vol.10, No.5, pp. 1- 15, 2018. 